Table 1 Point mutations in the Runt domain associated with blood or bone disease

\begin{tabular}{|c|c|c|c|c|c|}
\hline Mutation & Disease & Type & $\begin{array}{l}\text { DNA } \\
\text { binding }\end{array}$ & $\begin{array}{l}\text { Hetero- } \\
\text { dimerization }\end{array}$ & Ref. \\
\hline Arg $80 \rightarrow$ Cys & AML & Monoallelic & - & + & 3 \\
\hline Lys83 $\rightarrow$ Asn & AML & Monoallelic & - & + & 3 \\
\hline $\operatorname{Arg} 177 \rightarrow$ Gln & AML & Monoallelic & - & + & 3 \\
\hline Arg139 $\rightarrow$ Gln & FPD & Monoallelic & NT & NT & 2 \\
\hline $\operatorname{Arg} 174 \rightarrow$ Gln & FPD & Monoallelic & NT & NT & 2 \\
\hline Met124 $\rightarrow$ Arg & CCD & Monoallelic & - & NT & 5 \\
\hline Ser140 $\rightarrow$ Asn $^{a}$ & CCD & Monoallelic & - & - & 5 \\
\hline Phe146 $\rightarrow$ Ser $^{a}$ & CCD & Monoallelic & - & - & 7 \\
\hline Lys167 $\rightarrow$ Asn ${ }^{b}$ & CCD & Monoallelic & - & NT & \\
\hline $\operatorname{Arg} 174 \rightarrow \mathrm{Gln}^{\mathrm{b}}$ & CCD & Monoallelic & NT & NT & \\
\hline
\end{tabular}

AML, acute myelogenous leukemia; FPD, familial platelet disorder; $C C D$, cleidocranial dysplasia; NT, not tested; -, loss-of-function; +, similar to wild-type. Numbering according to AML1. DNA binding tested by electrophoretic mobility shift with recombinant protein; heterodimerization tested by electrophoretic mobility shift and/or affinity chromatography with recombinant protein. ${ }^{\text {aSer }} 140 \rightarrow$ Gly and Phe146 $\rightarrow$ Asp are deficient for both DNA binding and heterodimerization and were not isolated as being disease-related; the Asn and Ser mutations at these positions, respectively, have only been tested for DNA binding and are presumed to be heterodimerizationdeficient. ${ }^{b} \mathrm{H}$. Kanegene, personal communication. mosomal abnormalities in addition to AML1 mutations ${ }^{2}$. One possibility is that AML1 acts as a tumor suppressor. Haploinsufficency of a tumor suppressor could predispose patients to a variety of secondary mutations ${ }^{2}$. Alternatively, secondary defects may be linked to the TGF$\beta /$ BMP signaling cascade, which regulates cell proliferation and cell-fate determination. The Smad proteins interact with all three $\alpha$-subunit gene products and have a synergistic role in activating transcription (ref. 14; Y-W. Zhang and Y. Ito, personal communication).

The idea that heterozygous loss-offunction can result in a tumor-prone phenotype alters our concept of what it means for a protein to act as a tumor suppressor $^{15} \cdot \mathrm{p}^{2} 7^{\mathrm{Kip}}$, an inhibitor of cyclin-dependent kinases and suppressor of cell proliferation, is a second candidate tumor suppressor for which haploinsufficiency has been causally associated with tumor progression $^{16}$. To evaluate the role of tumor-suppressor haploinsufficiency in the development of heritable leukemias, it is important to determine whether or not the unaffected allele is fully functional. Secondary mutations, genetic and epigenetic mechanisms could all inhibit normal function of the wild-type gene product. Confirmation of AML1 haploinsufficiency in tumor cells may indicate new approaches to pharmacological intervention. A detailed characterization of the biochemistry of the normal and mutant gene products will be necessary for that take advantage of any biochemical differences between mutant and wildthe development of therapeutic agents
1. Look, A.T. Oncogenic transcription factors in the human acute leukemias. Science 278, 1059-1064 (1997).

2. Song, W.J. et al. Haploinsufficiency of CBFA2 causes familial thrombocytopenia with propensity to develop acute myelogenous leukaemia. Nature Genet. 23, 166-174 (1999).

3. Osato, M. et al. Biallelic and heterozygous point mutations in the runt domain of the AML1/PEBP $2 \alpha B$ gene associated with myeloblastic leukemias. Blood 93, 1817-1824. (1999)

4. Rodan, G.A. \& Harada, S-I. The missing bone. Cell 89, 6777-680 (1997).

5. Lee, B. et al. Missense mutations abolishing DNA binding of the osteoblast-specific transcription factor OSF2/CBFA1 in cleidocranial dysplasia. Nature Genet. 16, 307-310 (1997).
6. Mundlos, S. et al. Mutations involving the transcription factor CBFA1 cause cleidocranial dysplasia. Cell 89, 773-779 (1997)

7. Zhang, Y-W. et al. PEBP $2 \alpha \mathrm{A} / \mathrm{CBFA} 1$ mutations in Japanese cleidocranial dysplasia patients. Gene (in the press).

8. Nagata, T. et al. Immunoglobulin motif DNA recognition and heterodimerization of the PEBP2/CBF Runt domain. Nature Struct. Biol. 6, 615-619 (1999).

9. Goger, M. et al. Molecular insights into PEBP2/CBF $\beta$ $\mathrm{SMMHC}$ associated acute leukemia revealed from the structure of PEBP2/CBF $\beta$ Nature Struct. Biol. 6, 620-623 (1999).

10. Huang, $X$. et al. Solution structure of $C B F \beta$ and a map of the CBF $\alpha$ binding site. Nature Struct. Biol. 6, 624-627 (1999).

11. Berardi, M.J. et al. The lg fold of the core binding factor $\alpha$ Runt domain is a member of a family of structurally and functionally related Ig-fold DNA-binding domains. Structure 7, 1247-137 (1999).

12. Wang, Q. et al. Disruption of the CBFA2 gene causes tem and blocks definitive hematopoiesis. Proc. Natl. Acad. Sci. USA 93, 3444-3449 (1996).

13. Okuda, T. et al. AML1, the target of multiple chromosomal translocations in human leukemia, is essential for normal fetal liver hematopoiesis. Cell 84, 321-330 (1996).

14. Hanai, J. et al. Interaction and functional cooperation of PEBP2/CBF with Smads. J. Biol. Chem. 274, 31577-31582 (1999)

15. Knudson, A.G.Jr. Mutation and cancer: statistical study of retinoblastoma. Proc. Natl. Acad. Sci. USA 68, 820-823 (1971).

16. Fero, M.L. et al. The murine gene $p 27^{k i p 1}$ is haplo-insufficient for tumour suppression. Nature 396, 177-180 (1998).

${ }^{1}$ Laboratory of Molecular Biophysics

The Rockefeller University, 1230 York Avenue,

New York, New York 10021, USA

Email: mwerner@portugal.rockefeller.edu

${ }^{2}$ Departments of Viral Oncology, Genetics and

Molecular Biology, Institute for Virus Research,

Kyoto University, Sakyo-ku, Kyoto 606, Japan necrosis and hemorrhaging in the central nervous sys-

\section{Ancient HTLV-1}

The ancestors of the Andean indigenous people are believed to have originated in Asia and migrated to South America about 20,000 years ago. This explains their genetic similarities with the Japanese, including their similarity in human T-cell lymphotrophic virus type I (HTLV-1) haplotypes. To determine whether the ancient Andeans (Paleo-mongoloids) migrated with this HTLV-1 haplotype, Cartier et al. (page 1428, this issue) analyzed DNA isolated from bone marrow of mummies excavated from the Atacama desert in north Chile. People buried in cemeteries of this region were naturally mummified by the dry and salty conditions of the desert, and thousands of mummified bodies have been discovered. Two of 104 mummies tested actually had ancient HTLV-1 DNA, and these viral DNA sequences were almost identical to those of modern-day Chilean

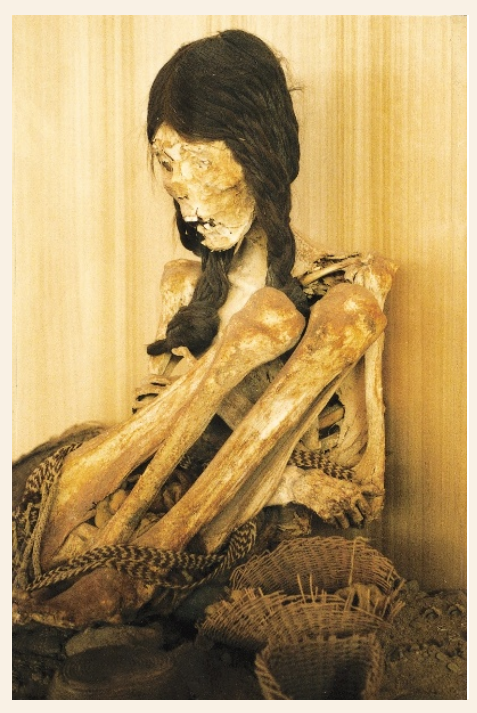
and Japanese HTLV-1-seropositive individuals. The authors suggest that the HTLV-1 provirus of these mummies might be the aboriginal HTLV-1 prevailing among Mongoloid populations in Asia and the Andes over 1,500 years ago. The picture shows one of the mummies from this region, a woman estimated to be 1,300-1,700 years old, at the Instituto de Investigaciones Arqueologicas y Museo in San Pedro de Atacama, Chile.

Kristine Novak 